7. Reprod. Fert. (1973) 33, 411-423

\title{
SYNERGISTIC EFFECTS OF TESTOSTERONE AND OESTROGENS ON ACCESSORY SEX GLANDS AND SEXUAL BEHAVIOUR OF THE BOAR
}

\author{
H. S. JOSHI* AND J. I. RAESIDE \\ Department of Biomedical Sciences, Ontario Veterinary College, \\ University of Guelph, Guelph, Ontario, Canada
}

(Received 24th April 1972)

Summary. The effects of oestrogens on the activity of accessory sex glands were studied in castrated boars receiving testosterone continuously. Diethylstilboestrol (DES), $17 \beta$-oestradiol $\left(\mathbf{E}_{2}\right)$ and oestrone $\left(\mathbf{E}_{1}\right)$ were administered successively for 6 -week periods which alternated with treatments of testosterone alone. Semen was collected twice each week and measurements were made of the total, the strained and the gel volumes. Citric acid and fructose contents of the seminal plasma were also determined. Highly significant $(P<0.01)$ differences between boars were observed for all criteria in a series of collections made before castration.

Gastration resulted in reduction in the total quantities of secretory products of the accessory sex glands. Subsequent treatment with testosterone alone for a period of 12 weeks had only a slight effect on their secretions. Supplementary treatment with DES, $\mathrm{E}_{2}$ or $\mathrm{E}_{1}$ significantly $(P<0.01)$ increased the secretory activity of these glands from the levels in the respective preceding periods with testosterone alone. After withdrawal of oestrogens, the elevated levels of citric acid secretion remained high or increased further, while the amounts of seminal plasma and fructose continued at the higher levels or declined.

Oestrogens also had a synergistic effect with testosterone on improving the libido of castrated boars. The reaction time was decreased by $45 \%$ $(P<0.01)$ during supplementary treatment with oestrone for 12 weeks.

The results of these experiments suggest that oestrogens act synergistically with testosterone on the accessory sex glands and on the sexual behaviour of the boar.

\section{INTRODUGTION}

Large quantities of oestrogens are present in the urine of the boar (Velle, 1958a, b; Raeside, 1965). Since the urinary excretion of oestrogens is greatly reduced after castration, the testes are thought to be the major source of oestrogens in this animal. Preliminary evidence has been given that boar testes produce

* Present address: Worcester Foundation for Experimental Biology, Shrewsbury Massachusetts 01545, U.S.A. 
oestrone sulphate and 17 $\beta$-oestradiol sulphate (Raeside, 1966), and both dehydroepiandrosterone (Baulieu, Fabre-Jung \& Huis in't Veld, 1967) and androstenediol (Raeside \& Howells, 1971) have been isolated as sulphates from the testes and spermatic vein blood of the boar. The significance of the unusual pattern of steroid secretion by the testes in this species is not known. It may be related to the extraordinarily large volume of seminal plasma which is a characteristic of the pig.

Oestrogens are generally thought to antagonize the action of testosterone on the accessory sex glands of the male (Price \& Williams-Ashman, 1961; Mann, 1964). The present investigation has demonstrated some synergistic effects of testosterone and oestrogens on the secretory activity of the accessory sex glands and on the sexual behaviour of the boar.

\section{Animals}

\section{MATERIALS AND METHODS}

Five Yorkshire boars were housed indoors in individual pens under conditions of moderate control of temperature. They were given 2.0 to $2.5 \mathrm{~kg}$ of a standard commercial ration (Shur-Gain, Canada Packers Ltd) twice daily, and water was available at all times.

\section{Collection of semen}

An iron-framed dummy sow, modelled after that of Aamdal \& Hogset (1957) was bolted to the floor in a separate enclosure and used as a teaser for training the boars. Semen was collected with an artificial vagina 15 to $18 \mathrm{~cm}$ in length which was lined by rubber tubing ( 25 to $30 \mathrm{~cm}$ long) with a rough surface inside. A plastic bottle of $500 \mathrm{ml}$ capacity was attached securely to the protruding end of the tube. Suitable pressure was obtained in the vagina by introducing warm water and air through a screw-type cap fitted with an air-valve. Boars were induced to ejaculate by grasping the spiral tip of the penis with fingers placed around the collection tubing. Rhythmic pulsating pressure was provided by the fingers during ejaculation. Training of boars and semen collections were carried out by one of us (H.S.J.) in order to avoid variations in techniques due to different operators. The behaviour of each animal was studied and indications of completeness of collection were noted, such as detumescence and withdrawal of the penis, and attempts to dismount and leave the collection area. Boars which were aggressive before and during ejaculation became easily manageable after the collection. Throughout the experiment every attempt was made to maintain uniformity in procedures.

\section{Experimental periods and treatments}

A duration of 6 weeks was taken as a suitable period for assessing the effect of a particular treatment. When the boars were suitably trained and well accustomed to the dummy and the operator, they were 10 to 13 months old and weighed 127 to $195 \mathrm{~kg}$. At the end of the experiment, 15 months later, they weighed 229 to $247 \mathrm{~kg}$. Semen was collected from the intact boars twice each week, that is, at 3-and 4-day intervals (Period 1). The boars were then castrated under pentobarbital sodium (Nembutal; Abbott Laboratories Ltd) anaesthesia, 
and antibiotic cover consisting of treatment with penicillin and streptomycin (Fortimycin; Ayerst, McKenna and Harrison Ltd) was given. Post-operative recovery was uneventful and seminal collections were resumed 1 week after castration. Every attempt was made to carry out collections regularly, but they could not be obtained on all occasions during the period immediately after castration (Period 2). At the end of this period, the boars were given testosterone (Repositol testosterone; Pitman-Moore Ltd) in a weekly dose of $37.5 \mathrm{mg} / \mathrm{boar}$ (Period 3), followed by weekly injections of $75 \mathrm{mg}$ for another 6 weeks (Period 4 ). Thereafter, the boars received $75 \mathrm{mg}$ testosterone (T) once a week for the remainder of the experiment. Supplementary treatment was given with diethylstilboestrol (DES), 3.7 mg (Period 5); $17 \beta$-oestradiol ( $\left.E_{2}\right), 7.5 \mathrm{mg}$ (Period 7); oestrone $\left(E_{1}\right), 15 \mathrm{mg}$ (Period 9) and oestrone, $30 \mathrm{mg}$ (Period 10). Testosterone alone was administered during Periods 6,8 and 11 .

Testosterone and diethylstilboestrol (Pitman-Moore Ltd) were obtained as aqueous-alcoholic solutions. The $17 \beta$-oestradiol (Steraloids Inc.) and oestrone (Ayerst Laboratories Ltd) were mixed with the testosterone solution just before use and were administered as a solution, or as a suspension in the case of the greater amounts of oestrone, in a single dose by deep intramuscular injection. The hormone preparations were given after the first seminal collection had been made each week.

\section{Criteria used for assessment of hormone treatment}

Semen or seminal plasma volume. Semen and seminal plasma volumes were measured with graduated cylinders and recorded as total volumes. Each seminal collection was immediately filtered and squeezed through double-layered cheese-cloth to remove the gel portion. The volume of the filtrate was recorded as the strained volume of seminal plasma, and the difference between the total and the strained volumes was noted as the gel volume. Aliquots were taken after thorough mixing of the strained seminal plasma, and stored at $-20^{\circ} \mathrm{G}$ until analysed for citric acid and fructose.

Citric acid and fructose. Since the gel is devoid of citric acid and fructose (Mann, 1964), chemical analyses were carried out on aliquots of strained seminal plasma. A few analyses were made on the water washings of the gel at the beginning of the investigation and only traces of fructose and citric acid were found. Citric acid was determined according to the procedure outlined by Ettinger, Goldbaum \& Smith (1952) and fructose analyses were carried out by the method described by Mann (1964).

Reaction time. Timing was commenced immediately after the boar had entered the collection area. In most instances, manipulations over the preputial area of the boar were needed to induce the animal to mount the dummy. As soon as the boar had mounted and shown erection of the penis, the time was again noted. This interval was recorded as the reaction time and taken as a measure of the influence of castration and of treatment with testosterone and oestrogens on the libido of the boars.

\section{Statistical analysis}

Data were subjected to an analysis of variance (Snedecor, 1956). Since the 


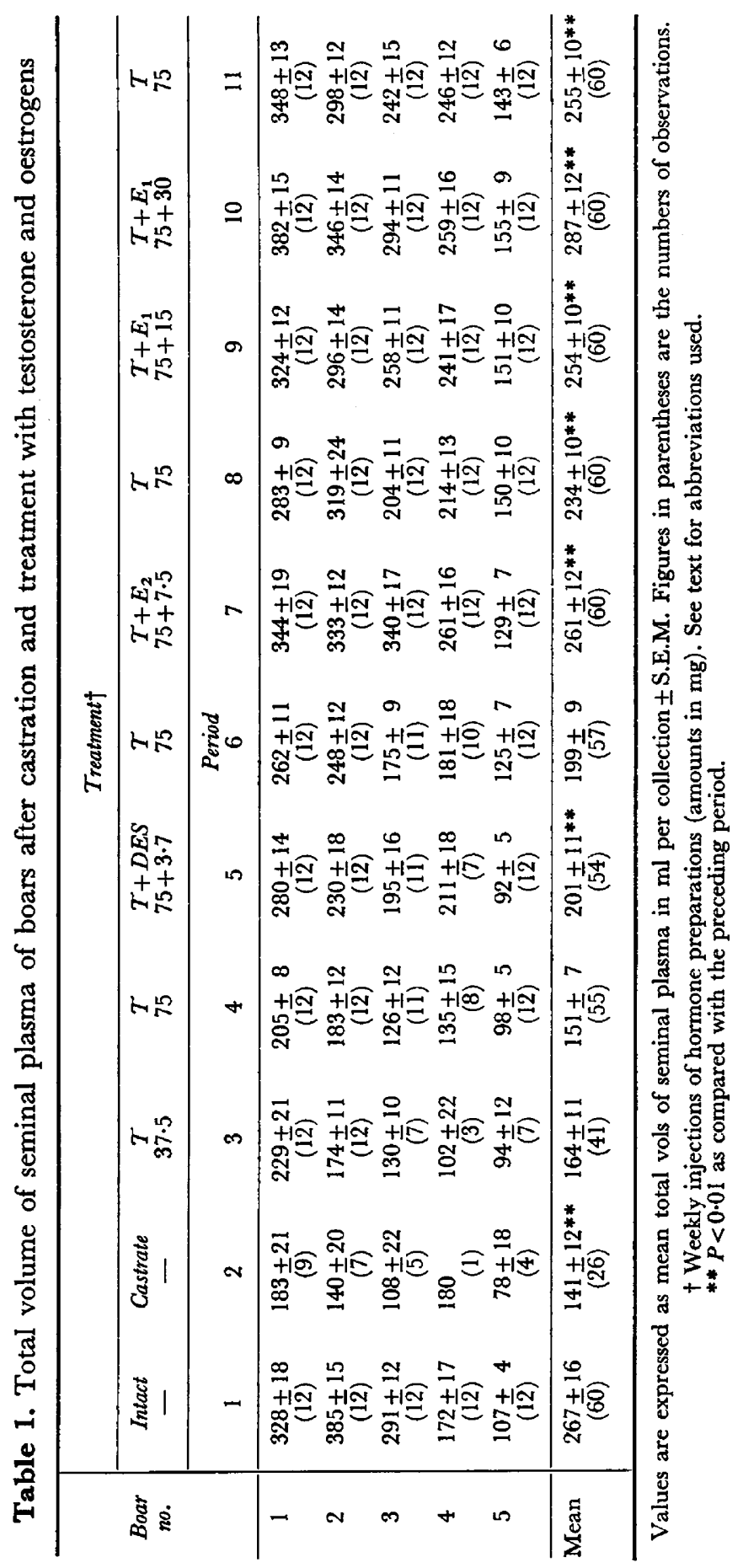


boars had shown marked differences between animals in the volume and composition of semen during the initial period, each boar was included in the entire series of treatments. Mean values for each criterion in succeeding treatment periods were compared with those of the immediately preceding period, for all five boars as a group. Such comparisons were made to accommodate the possible influence of the previous hormone treatment and of the increasing age of the boars on the response to the hormones given in each period.

\section{RESULTS}

\section{Seminal plasma volume}

Observations are summarized in Tables 1 to 4 and in Text-fig. 1. Presentation of some of the findings in graphical form (Text-fig. 1) serves especially to reveal trends within treatment periods; the data given in the tables allow statistical comparisons between treatment periods and, at the same time, provide information complementary to that in the graphs. The results show that during the 'intact' period, there were marked differences between boars in the semen volume (Table 1). To a large extent, these differences persisted throughout the experiment. The mean total volume decreased significantly $(P<0.01)$ during the 'castrate' period. Treatment with testosterone, even in the larger amounts, did not cause a significant increase in the total volume. Supplementary treatment with DES, $\mathbf{E}_{2}$ or $\mathbf{E}_{1}$ (Periods 5,7 and 10 ) increased the total volumes $(P<0.01)$, as compared with those in the preceding periods of treatment with testosterone alone (Periods 4, 6 and 8, respectively). Comparisons between treatments with testosterone plus oestrogens (Periods 5, 7 and 10) and succeeding treatments with testosterone alone (Periods 6, 8 and 11) demonstrated that the mean total volume was maintained after withdrawal of DES, while the volumes were reduced $(P<0.01)$ after withdrawal of $E_{2}$ and $E_{1}$.

Changes in the strained volume of seminal plasma after castration, during treatment with testosterone alone, and with testosterone in combination with oestrogens, were essentially similar to those observed for the total volume. Graphical presentation of the data on the average strained volume for the five boars on each day of collection (Text-fig. 1) showed that castration resulted in a decrease in the strained volume to about one-third of the volume before surgery. During the treatment with testosterone which followed there was only a slight increase. Supplementary treatment with oestrogens caused the volume to increase and reach values about $110 \%$ (Period 10) of those in the period before castration. Withdrawal of oestrogens resulted in either a 'levelling-off' (Period 6), or a tendency to decrease (Periods 8 and 11).

After castration, the mean volume of the gel fraction decreased slightly $(P<0.05$, Table 2$)$. It was restored initially by testosterone administration but showed a decline while the animals were receiving the lower amounts of testosterone. The volumes remained low even when larger quantities of testosterone were given alone (Period 4). Supplementary treatment with DES brought about a significant $(P<0.01)$ increase, but no striking changes in gel volume were seen subsequently. 
Citric acid and fructose

Castration of boars resulted in an increase in the citric acid concentration (Table 3) but caused a decrease in its total amount in the seminal plasma (Textfig. 1). Treatment with testosterone alone had little effect on the total quantities. However, supplementary treatment with DES, $E_{2}$ or $E_{1}$ resulted in a marked increase in the citric acid content and, with $\mathrm{E}_{2}$, there was also an increase in the concentration. After withdrawal of oestrogens, the amounts of citric acid either
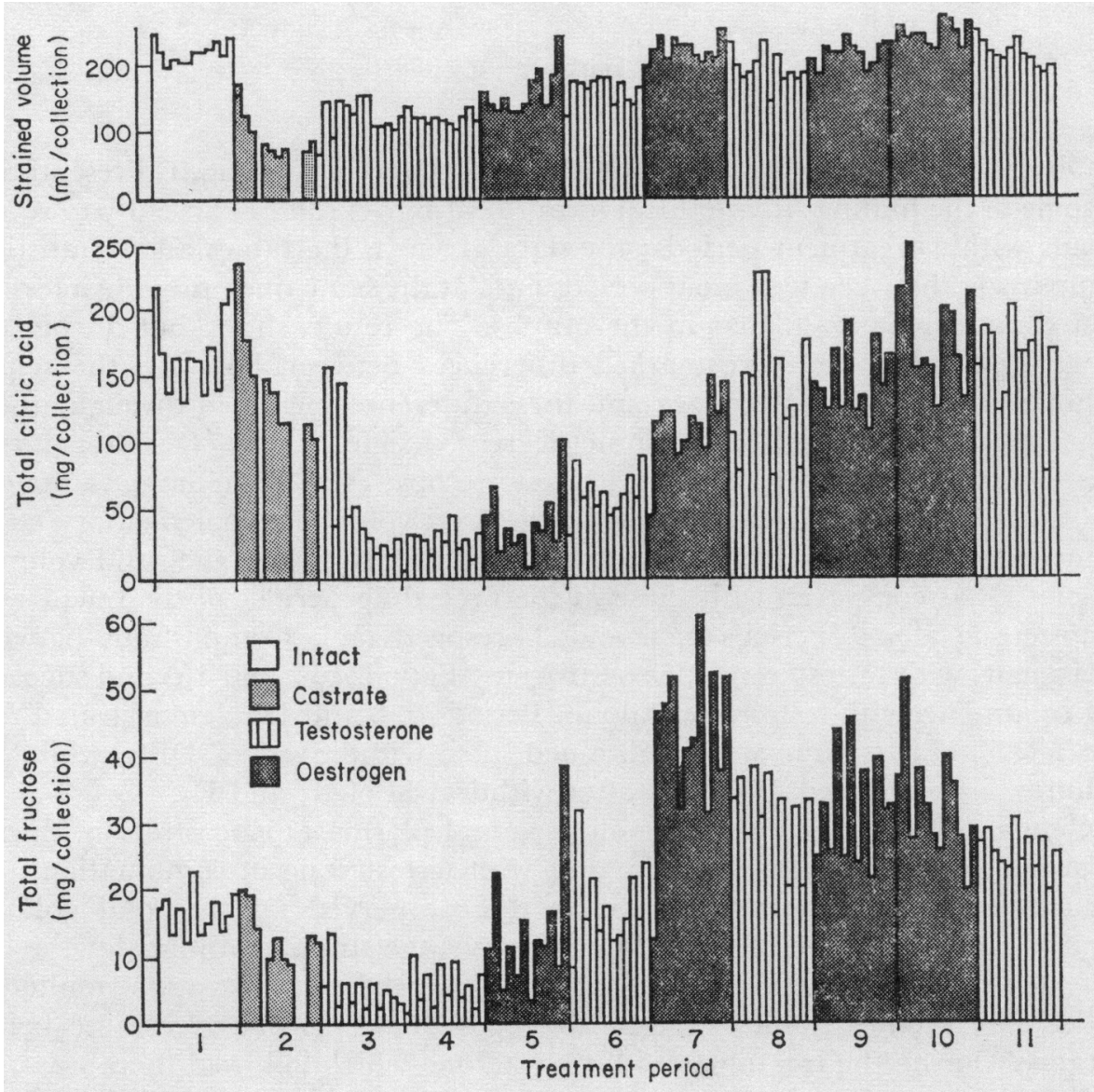

TexT-FIG. 1. Effects of testosterone and oestrogens on the activity of the accessory sex glands of castrated boars, expressed as mean values for the boars on each day of collection. Details of treatment are given in the text.

continued to increase (Periods 6 and 8 ) or were maintained at higher values (Period 11).

Changes in the fructose content of the seminal plasma showed a pattern similar to that of the citric acid analyses (Text-fig. 1). The treatment with $\mathrm{E}_{2}$ especially resulted in a large increase in the fructose content and concentration (Table 4), when compared with the preceding treatment with testosterone alone. After withdrawal of DES, the amounts of fructose in the seminal plasma 


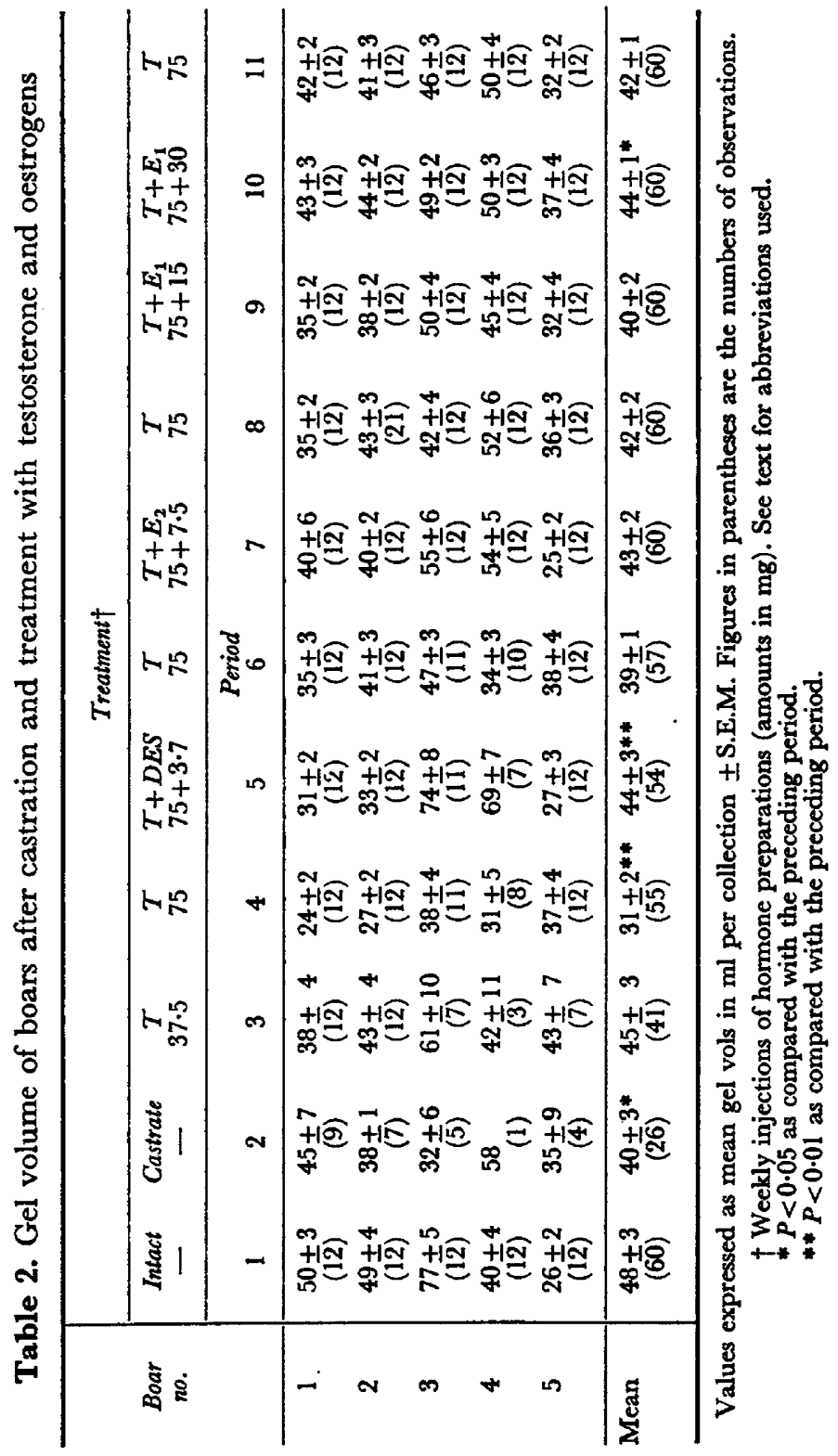




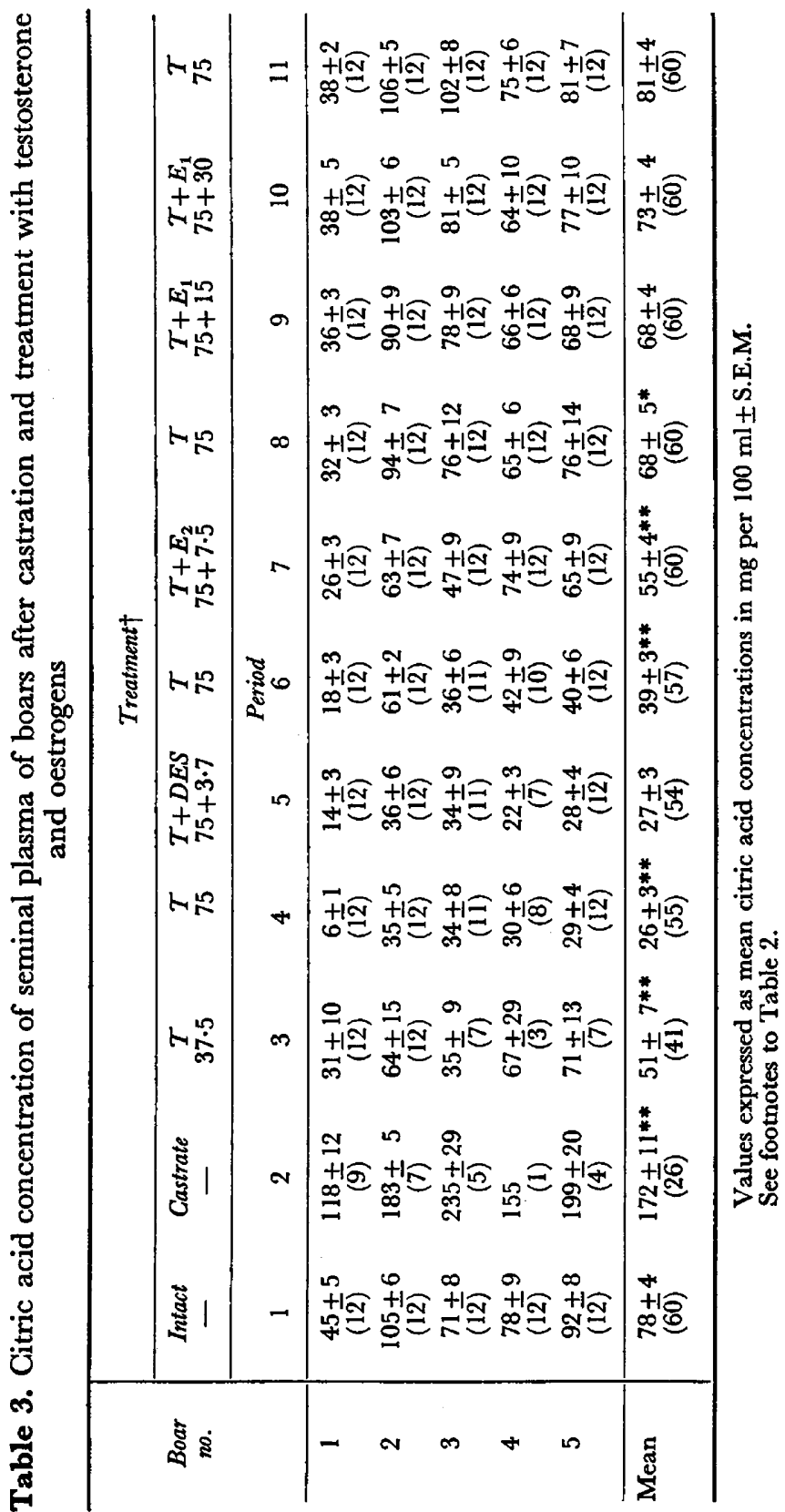




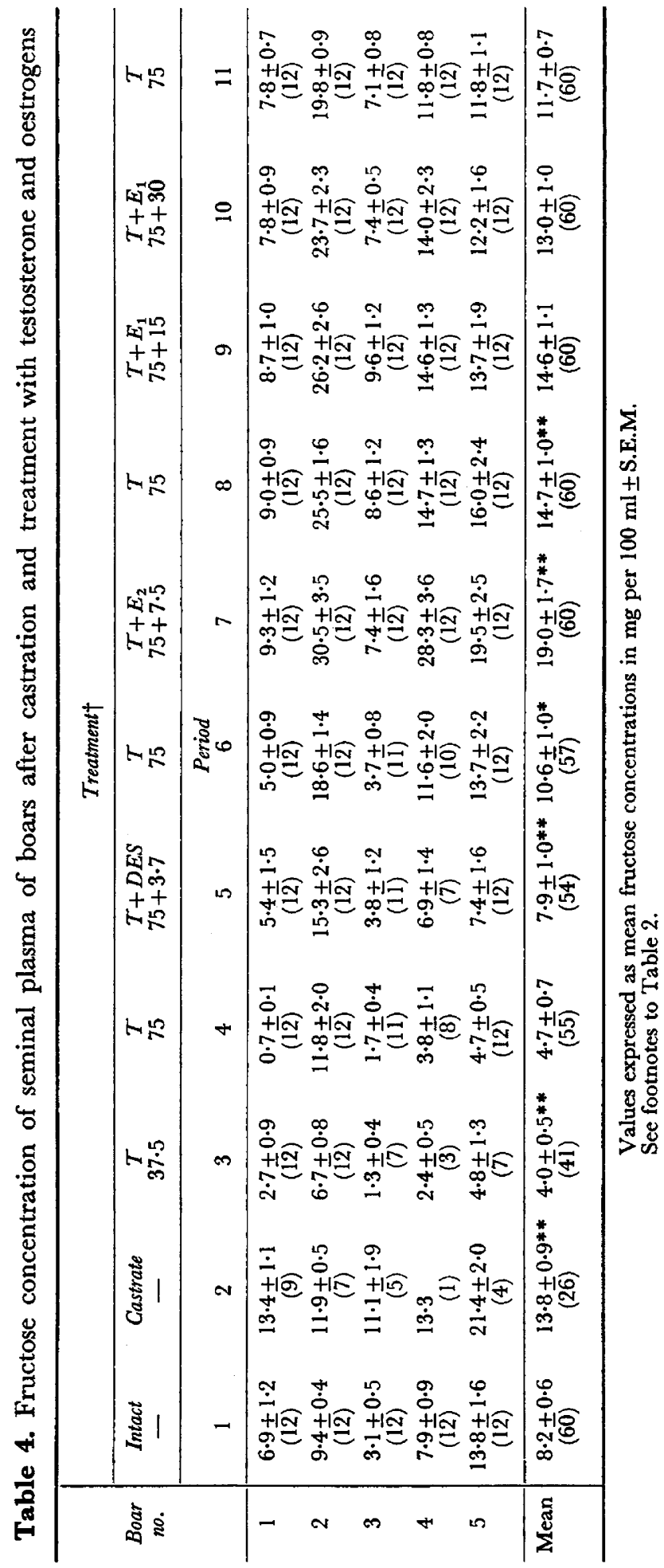


remained at higher levels, whereas withdrawal of $E_{2}$ or $E_{1}$ resulted in decreases in fructose.

\section{Reaction time}

The overall mean values for reaction time during different treatments are shown in Text-fig. 2. Castration resulted in a great increase in reaction time. Supplementary treatment with DES, $\mathrm{E}_{2}$ or $\mathrm{E}_{1}$ caused a decrease, in each instance, from that seen during the preceding treatments with testosterone alone. The continued administration of oestrone at higher levels for another 6 weeks (Period 10) resulted in a further decrease and brought the values down to those observed before castration. Withdrawal of oestrogens from the hormone treatment tended to increase the reaction time at each occasion.

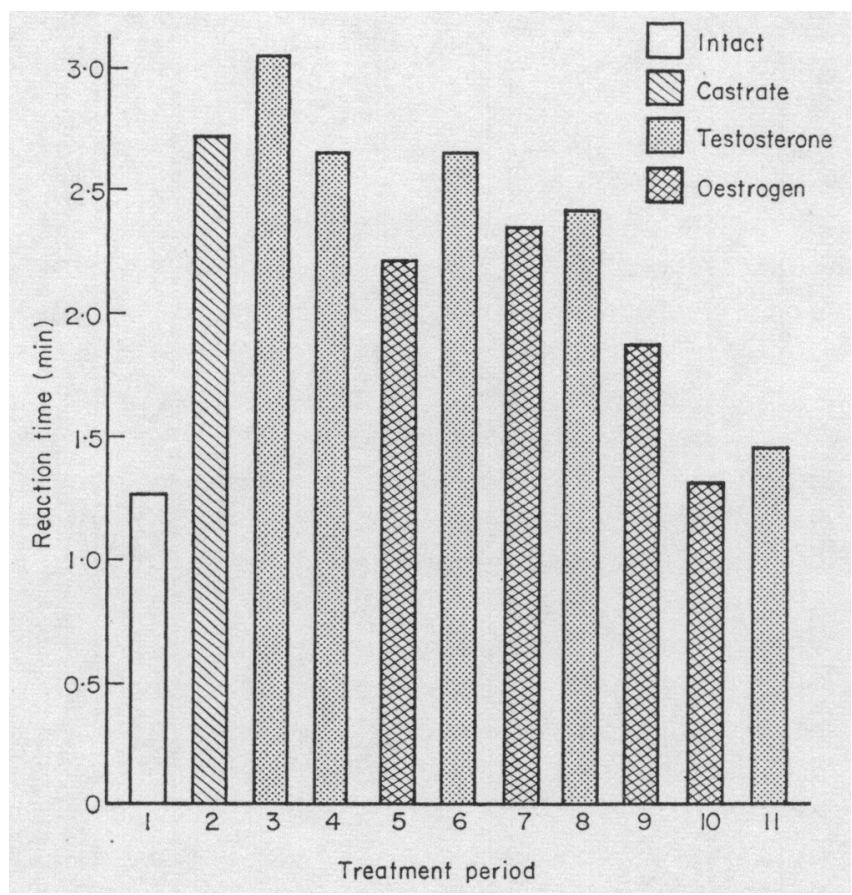

Texr-fig. 2. Effect of testosterone and oestrogens on the sexual behaviour of castrated boars, expressed as the mean value of all measurements for the boars in each treatment period. Details of treatment are given in the text.

\section{DISCUSSION}

It is well known that castration produces atrophic changes in the accessory sex glands of the male and a great reduction in secretory activity. These changes are reversed by testosterone administration (Price \& Williams-Ashman, 1961; Mann, 1964). On this basis, the amounts of citric acid and fructose in the semen of mammals have been used widely as indicators of androgenic activity (Mann, 1964). In the present investigation, castration resulted in a decreased secretory activity of the accessory sex glands of boars, as shown by a reduction 
in the volume of the seminal plasma and in the levels of citric acid and fructose. Hupp, Andrews \& Murphree (1961) reported similar findings in an earlier study in which five mature boars were given testosterone therapy commencing about 3 weeks after castration. In addition, they found that increased doses of testosterone failed to bring about increased fructose levels, and that larger doses of testosterone were required to restore fructose levels in two animals which had been castrated for 2 months. From their observations, it was concluded that changes not reversible by testosterone took place following castration. Treatment with testosterone alone in the doses given to our animals, which had been castrated for 6 weeks, had only limited effects on the secretions over a period of 12 weeks (Periods 3 and 4), and amounts remained below the precastration levels. During supplementary treatment with oestrogens, the products of the accessory glands increased consistently and reached values equal to, or above in the case of fructose, those seen in the period before castration (Text-fig. 1). These results suggest a synergistic effect of testosterone and oestrogens on the secretory activity of the various accessory sex glands of the boar, and may explain, in part, the failure of testosterone therapy to restore activity to that normal for an intact boar.

After the several withdrawals of oestrogens, the amounts of the secretory products generally tended to decline, indicating that the treatments with testosterone alone were unable to sustain the higher levels of secretory activity noted when an oestrogen was injected with testosterone. It was observed also that the levels usually did not drop to those of the preceding treatments with testosterone alone. There seemed to be a 'carry-over' effect from a period of oestrogen administration to the succeeding treatment with testosterone alone. Despite the elevated levels in the later stages of the experiment, oestrogens were able to stimulate the sex accessory glands still further and thereby add to the evidence for a synergism.

Wallace (1949) reported that stilboestrol given to mature boars had no apparent effect on the volume of the semen. As intact boars were used in her experiment, the results cannot be compared directly with those of the present study in which castrated animals were treated. Synergistic effects of testosterone and oestrogens on the levels of citric acid, or of fructose, have been reported in castrate males of other species. Gassner, Hill \& Sulzberger (1952) noted an enhancement of the stimulatory action of testosterone on the fructose concentration of the seminal plasma of castrated bulls when supplementary oestradiol propionate was given. Grayhack (1965) found that both the citric acid content and concentration in the lateral lobes of the prostate glands of rats treated with testosterone and $17 \beta$-oestradiol were significantly greater than in those of rats injected with testosterone alone. Thomas \& Knych (1966) observed a synergistic effect of testosterone and oestrogens on the fructose levels of the seminal vesicles of castrated mice. In our own studies with rats, a synergistic effect was shown for testosterone and oestrogens on the citric acid levels of the accessory sex glands of castrated males (Joshi, 1971).

Testosterone administration is well known to increase sexual desire in castrated males. On the other hand, the effects of oestrogens on sexual behaviour in the male are less clear. Foss (1939) reported that the copulatory power of a 
castrated man was increased when oestradiol benzoate was added to the testosterone treatment. In contrast, Grant, Griffiths \& Pierrepoint (1967) noted reduced libido in a human male with a feminizing testicular tumour. For the boar, Wallace (1949) recorded that the libido of intact mature animals was relatively less adversely affected by stilboestrol implants than by castration. Stilboestrol implantation has been reported to result in regained capability for erection of the penis and in arousal of sexual desire of young, castrated male pigs (Dinusson, Klosterman \& Buchanan, 1951). From the present experiment, it was concluded that a synergistic effect was shown for testosterone and oestrogens in improving the libido of castrated boars.

The synergistic effects of testosterone and oestrogens on the accessory sex glands and on the sexual behaviour of the boar are particularly interesting in view of the large quantities of oestrogens produced by males of this species (Velle, 1958a, b; Raeside, 1965). If much of this oestrogen production occurs in the form of a secretion of oestrogen sulphates by the testes, as seems likely in the stallion (Raeside, 1969), then a physiological rôle for oestrogen sulphate secretion should be sought in the boar. Our preliminary studies, using oestrone sulphate and dehydroepiandrosterone sulphate to supplement testosterone treatment, suggested a stimulatory action for the sulphoconjugated steroids on the accessory sex glands of castrated boars (Joshi, 1971). Further experiments of this nature are required to provide an answer, and might help also towards a better understanding of the biological significance of steroid sulphate secretion in general (Wang \& Bulbrook, 1968).

\section{AGKNOWLEDGMENTS}

The authors wish to express thanks to Mrs June Watt, Mr J. Bosman and $\mathrm{Mr}$ G. Rossit for assistance with the experimental animals. The work was supported by the Ontario Department of Agriculture and Food, and by a grant from the Canada Department of Agriculture.

\section{REFERENGES}

Aamdal, J. \& Hogset, I. (1957) Artificial insemination in swine. F. Am. vet. med. Ass. 131, 59.

Baulieu, E. E., Fabre-Jung, I. \& Huis in't Veld, L. G. (1967) Dehydroepiandrosterone sulfate: a secretory product of the boar testis. Endocrinology, 81, 34 .

Dinusson, W. E., Klosterman, E. W. \& Buchanan, M. L. (1951) Stilbestrol, effect of subcutaneous implantation on growing-fattening swine. F. Anim. Sci. 10, 885.

Ettinger, R. H., Goldbaum, L. R. \& Smith, L. H., JR (1952) A simplified photometric method for the determination of citric acid in biological fluids. F. biol. Chem. 199, 531 .

Foss, G. L. (1939) Clinical administration of androgens. Lancet, 236, 502.

Gassner, F. X., Hill, H. J. \& Sulzberger, L. (1952) Relationship of seminal fructose to testis function in the domestic animal. Fert. Steril. 3, 121.

Grant, J. K., Griffiths, K. \& Pierrepoint, G. G. (1967) Steroid biosynthesis in abnormal testis. Ciba Fdn Colloq. Endocr. 16, 280.

Grayhack, J. T. (1965) Effect of testosterone-estradiol administration on citric acid and fructose content of the rat prostate. Endocrinology, 77, 1068.

Hupp, E. W., ANdrews, J. F. \& Murphree, R. L. (1961) Effect of exogenous testosterone on fructose and citric acid of swine semen. F. Anim. Sci. 20, 774.

JosHI, H. S. (1971) Synergistic effects of testosterone and estrogens on male accessory glands of castrated rats and boars. Ph.D. thesis, University of Guelph.

MANN, T. (1964) The biochemistry of semen and of the male reproductive tract. John Wiley and Sons, New York. 
Price, D. \& Williams-Ashman, H. G. (1961) The accessory reproductive glands of mammals. In: Sex and Internal Secretions, 3rd edn, Vol. 1, p. 366. Ed. W. C. Young. Williams \& Wilkins, Baltimore.

RAESIDE, J. I. (1965) Urinary excretion of dehydroepiandrosterone and oestrogens by the boar. Acta endocr., Copenh. 50, 611.

RAEsIDE, J. I. (1966) Secretion of steroid sulphates by the testes of the boar. In: Proceedings of the Canadian Federation of Biological Societies, Vol. 9, p. 52. Ed. K. K. Garroll. Hunter Printing Ltd, London and Ontario.

Rasside, J. I. (1969) The isolation of estrone sulfate and estradiol-17 $\beta$ sulfate from stallion testes. Can. $\mathcal{F}$. Biochem. 47, 811 .

RAeside, J. I. \& Howells, G. A. (1971) The isolation and identification of androstenediol sulfate from spermatic vein blood and testes of the boar. Can. 7. Biochem. 49, 80.

SNedeCOR, G. W. (1956) Statistical methods. Iowa State University Press, Ames, Iowa.

Thomas, J. A. \& KNYCH, E. T., JR (1966) Further studies on the influence of oestrogens on androgen dependent fructose formation in sex accessory organs. Acta endocr., Copenh. 53, 455.

Velle, W. (1958a) Isolation of oestrone and oestradiol-17 $\beta$ from the urine of adult boars. Acta endocr., Copenh. 28, 255.

VELLE, W. (1958b) Further studies on urinary oestrogen excretion by the boar. Acta endocr., Copenh. 29, 395.

WALLACE, C. (1949) The effects of castration and stilboestrol treatment on the semen production of the boar. F. Endocr. 6, 205.

WANG, D. Y. \& Bulbrook, R. D. (1968) Steroid sulphates. In: Advances in Reproductive Physiology, Vol. 3, p. 113. Ed. A. McLaren. Logos Press, London. 